\title{
CARING THROUGHOUT LIFE: \\ PECULIARITIES OF LONGTERM CARE FOR PUBLIC POLICIES WITHOUT AGEISM
}

Cuidar ao longo da vida: peculiaridades do cuidado de longa duração para políticas públicas livres de preconceito etário

Karla Cristina Giacomin ${ }^{\mathrm{a}}$ (1), Paulo José Fortes Villas Boas ${ }^{\mathrm{b}}$ (1), Marisa Accioly Rodrigues da Costa Domingues ${ }^{c}$ (D), Patrick Alexander Wachholz ${ }^{\mathrm{b}}$

\author{
On behalf of the Frente Nacional de Fortalecimento à ILPI
}

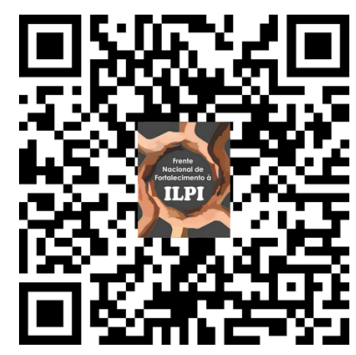

The worldwide population aged 80 and over is growing at a faster pace than in the past, particularly in developing countries. ${ }^{1}$ However, the gap between increased and healthy life expectancies seems to have deepened: the added years are marked by poor health, social isolation, or dependency on care. ${ }^{2}$ Thus, the need for long-term care (LTC) is expected to increase significantly. ${ }^{3}$

Low- and middle-income countries (LMIC) are at different stages of preparedness for dealing with the aging population and the needs of the LTC sector. ${ }^{4}$ Despite macro-social, economic and health advances, access to LTC facilities and the quality and affordability of care do not seem to have improved globally.

According to the Organization for Economic Co-operation and Development, LTC encompasses

a range of medical, personal care, and assistance services that are provided with the primary goal of alleviating pain and reducing or managing the deterioration in health status for people with a degree of long-term dependency, assisting them with their personal care. ${ }^{5}$

In 2015, the International Labour Office examined LTC protection in 46 LMIC, covering $80 \%$ of the world's population. According to their results, "the troubling situation of LTC observed at the global, regional and national level can be explained

aNúcleo de Estudos em Saúde Pública e Envelhecimento, Fundação Oswaldo Cruz - Belo Horizonte (MG), Brazil.

'Internal Medicine Department, Botucatu Medical School, Universidade Estadual Paulista “Júlio de Mesquita Filho" - Botucatu (SP), Brazil.

'Escola de Artes, Ciências e Humanidades, Universidade de São Paulo - São Paulo (SP), Brazil.

Correspondence data

Patrick Alexander Wachholz - Faculdade de Medicina, Universidade Estadual Paulista “Júlio de Mesquita Filho" - Avenida Professor Mário Rubens Guimarães Montenegro, s/n - Rubião Júnior - CEP: 18618687 - Botucatu (SP), Brazil. E-mail: patrick.wachholz@unesp.br @DrPatrickLTC Received on: 06/22/2019. Accepted on: 01/08/2020

How to cite this article: Giacomin KC, Boas PJFV, Domingues MARC, Wachholz PA. Caring throughout life: peculiarities of long-term care for public policies without ageism. Geriatr Gerontol Aging. 2021;15:e0210009. https://doi.org/10.5327/Z2447-21232021EDITESP

https://doi.org/10.5327/Z2447-21232021EDITESP 
in the context of both age and gender discrimination."They reported that about $46 \%$ of older people worldwide are excluded from any LTC coverage. ${ }^{6}$

The ineffectiveness (or nonexistence) of public policies targeting the LTC sector is evident in many LMIC countries. The inappropriate use of acute care hospital services and emergency departments is much higher among the oldest old where the LTC sector is underdeveloped or absent. ${ }^{3}$

Ageism, a pervasive phenomenon found in numerous settings, has led to social prejudice and bias in the healthcare system, ${ }^{7}$ including inequities and barriers to access or denial of treatment and healthcare services. ${ }^{8}$ Particularly in LTC facilities, ageism is strong predictor of worse health outcomes, including decreased survival, poorer quality of life, increased cognitive and functional impairment, and higher medication noncompliance rates, emergency visits, and hospitalizations. ${ }^{9}$

Despite being a complex concept difficult to evaluate and measure, age-based discrimination depends on stereotyping and is strongly influenced by social inequalities. ${ }^{7}$ Although under-theorized and poorly conceptualized, ${ }^{10,11}$ it can be defined as:

negative or positive stereotypes, prejudice and/or discrimination against (or to the advantage of) us on the basis of our chronological age or on the basis of a perception of us as being' old,' 'too old,' 'young' or 'too young.' Ageism can be self-directed or other-directed, implicit or explicit, and can be expressed on a micro, meso or macro-level. ${ }^{11}$

As in many other countries, there is no federally mandated coverage in Brazil to support the aging population in need of LTC. According to the 1988 Federal Constitution, the 1994 National Policy for Older People, and the 2003 Older Adult's Bill of Rights, LTC facilities should only be offered "in the presence of poverty, abandonment, or lack of family."

While the Brazilian constitution assigns the responsibility of LTC to families, there is a lack of government support for family care. Furthermore, there is substantial prejudice against institutional care. The few governmental actions addressing people in need of LTC facilities have focused on sheltering older people in economic deprivation. As a result, Brazil's LTC homes are scarce, public LTC expenditure per older adult practically do not exist, and it is estimated that at least 600,000 formal LTC workers are needed to fill the gap. ${ }^{12}$

Disregarding the peculiarities and internal processes of LTC facilities could lead to institutional violence and maltreatment. Without appropriate public policies, ageism may perpetuate obsolete or missing operational rules, which prevent the introduction of best practices for person-centered care and improved quality of care in LTC settings.

Ageism in LTC facilities has multiple faces that can manifest through:

- ignorance of the care needs of older people and their systematic exclusion from social protection and participation;

- social exclusion of older persons and a lack of empowerment through rights and voice;

- failure to recognize the potential for physical and mental improvement through providing quality services and enabling environments;

- a highly irrational fear of unaffordable public LTC expenditures due to aging populations;

- a scarcity of research and national datasets on LTC worldwide;

- a lack of social criticism about other forms of discrimination;

- a perception that older persons in need of LTC are a burden, which allows for lack of formal services to become the rule, leading to inaccessibility to LTC, as well as fraud, abuse, and violence against older persons;

- providing the same care to all LTC residents, irrespective of individual wants and needs; an institutional culture that does not support person-centered care.

Particularly in LMIC, inclusive and non-ageist public policies should allow unregistered LTC facilities to enter the health authorities' radar (not only for inspection purposes) and be protected and supported by the social support network. Likewise, private LTC facilities (ie, the majority of facilities in most LMIC) should be perceived as social protection institutions. Despite advancements in the for-profit sector in some countries, most private facilities in LMIC are small and highly vulnerable to both economic instability and more extensive health care demands, such as those caused by the COVID-19 pandemic.

While COVID-19 has brought ageism and LTC facilities into headlines, it has also provided an unprecedented opportunity to improve health outcomes. ${ }^{8}$ In some countries, older residents and LTC workers were included as a priority group for immunization. However, in others, they were regarded as groups of lesser clinical vulnerability according to clearly ageist criteria.

The World Health Organization ${ }^{4}$ included access to LTC and person-centered integrated care and primary health services as main areas for action for this Decade of Healthy Aging (2020 - 2030). Primary health care must be responsive to the needs of older people in order to shape 
and foster integrated health and LTC systems. This will involve national, subnational, and local governments, service providers, civil society, the private sector, organizations for older people, academia, and older people, as well as their families and friends. ${ }^{4}$

Despite evidence that ageism impacts the LTC sector, leading to inadequate or inappropriate care, LMIC have consistently failed to build an age-friendly healthcare system regarding LTC. Since we still do not know which interventions effectively prevent and fight ageism, ${ }^{11}$ it is essential to discuss and implement federal policies for LTC that involve aspects of social assistance and health. In addition, the lack of coordination between the different public management levels and between the health and social service sectors must be discussed and addressed.

Finally, disregarding the peculiarities of LTC also engenders institutional violence due to difficulties in access to primary inputs in both for-profit and non-profit facilities, which impacts the mental health of LTC professionals and managers. It is the role of academia, researchers, organized society, government institutions, and stakeholders to discuss the implementation of non-ageist public policies for the LTC of older people and to promote and value their inclusion in this process.

\section{CONFLICTS OF INTEREST}

The authors declare no conflicts of interest.

\section{FUNDING}

This study received no specific grants from funding agencies in the public, commercial, or not-for-profit sectors.

\section{AUTHOR CONTRIBUTIONS}

KCG: conceptualization, writing - original draft, writing - review \& editing. PJFVB: conceptualization, writing original draft, writing - review \& editing. MARCD: conceptualization, writing - original draft, writing - review $\&$ editing. PAW: conceptualization, writing - original draft, writing - review \& editing.

\section{REFERENCES}

1. United Nations. World Population Ageing 2019: Highlights. United Nations; 2019.

2. Beard JR, Officer AM, Cassels AK. The World Report on Ageing and Health. Gerontologist. 2016;56(Suppl. 2):S163-6. https://doi. org/10.1093/geront/gnw037

3. United Nations. The growing need for long-term care assumptions and realities. Available from: https:/www.un.org/esa/socdev/ageing/ documents/un-ageing_briefing-paper_Long-term-care.pdf. Accessed in Feb 22, 2021.

4. World Health Organization. Decade of Healthy Ageing 2020-2030. Available from: https://www.who.int/docs/default-source/decadeof-healthy-ageing/final-decade-proposal/decade-proposal-finalapr2020-en.pdf. Accessed in Jan 7, 2021.

5. Organization for Economic Co-operation and Developmen. OECD Health Statistics 2020 Definitions, Sources and Methods. Available from: http://stats.oecd.org/wbos/fileview2.aspx?IDFile=be9656b87f61-4a03-a1fc-bc503f459749\#: :text=Long\%2Dterm\%20care\%20 (health\%20and,them\%20with\%20their\%20personal\%20care\%20(. Accessed in Feb 22, 2021.

6. Scheil-Adlung $X$. Long-term care protection for older persons: A review of coverage deficits in 46 countries. Available from: http://www.ilo.org/wcmsp5/groups/public/---ed_protect/--soc_sec/documents/publication/wcms_407620.pdf. Accessed in Feb 22, 2021.
7. Goldani AM. "Ageism" in Brazil: what is it? who does it? what to do with it? Rev Bras Estud Popul. 2010;27(2):385-405. https://doi. org/10.1590/S0102-30982010000200009

8. Inouye SK. Creating an anti-ageist healthcare system to improve care for our current and future selves. Nat Aging [Internet] 2021 [Accessed in 2021 Feb 17]; 1. Available in: http://www.nature.com/articles/s43587020-00004-4. https://doi.org/10.1038/s43587-020-00004-4

9. Chang E-S, Kannoth S, Levy S, Wang S-Y, Lee JE, Levy BR. Global reach of ageism on older persons' health: A systematic review. PLoS One. 2020;15(1):e0220857. https://doi.org/10.1371/journal.pone.0220857

10. Ayalon L, Tesch-Römer C, editors. Contemporary Perspectives on Ageism. Available from: http://link.springer.com/10.1007/978-3319-73820-8. Accessed in Feb 17, 2021.

11. São José JMS de, Amado CAF. On studying ageism in long-term care: a systematic review of the literature. Int Psychogeriatr 2017;29(3):373-87. https://doi.org/10.1017/s1041610216001915

12. Camarano AA. Long-Term Care for Brazilian elders: a new social risk to be managed by the State? - International Long-term Care Policy Network ILPN. Available from: https://www.lpnetwork.org/ presentation/long-term-care-for-brazilian-elders-a-new-social-riskto-be-managed-by-the-state/. Accessed in Mar 8, 2021.

13. Lloyd-Sherlock P. Beyond Neglect: Long-term Care Research in Low and Middle Income Countries. Int J Gerontol. 2014;8(2):66-9. https://doi.org/10.1016/j.ijge.2013.05.005 